\title{
Interactive Monitoring and Controlling System for A Conference Hall
}

\author{
Arya R Nair, Rahul S Biju, Swetha Jose, V. S Devu; Sheenu P \\ UG Students \\ Department of Electrical and Electronics Engineering \\ Mar Baselios college of Engineering and Technology \\ Nalanchira, Trivandrum, Kerala, India. \\ Assistant Professor \\ Department of Electrical and Electronics Engineering \\ Mar Baselios College of Engineering and Technology \\ Nalanchira, Trivandrum, Kerala, India.
}

\begin{abstract}
Creating more astute gathering rooms in workplaces have an incredible breadth for advancement and computerized change. In this undertaking, we have built up a Smart Conference Room (SCR) design and tended to different approaching issues relating to a gathering room condition by giving mechanization. In the task, numerous detecting, handling and activation units have been created and sent. In our task we have built up a model of a framework where a solitary client can control the activities of light and fan utilizing a solitary LCD show. A speaker is a additionally joined which gives an invite note and a card to say thanks. This speaker joined can likewise be constrained by the LCD show. The fundamental bit of leeway of this venture is that a solitary client can control the activity of light, fan and speaker utilizing a solitary LCD. This model can likewise detect the temperature and dampness and show it on the screen. So as to assess our methodology, we follow a subjective assessment performed by genuine clients of the Smart Room.
\end{abstract}

Index Terms - Smart conference room, liquid crystal display.

\section{INTRODUCTION}

The smart room is a constant framework which capacities as per the necessities of the client. It makes a realtime connection between the machines and the customers. Different sensors for instance, temperature, humidity, light and so forth are utilized to follow. A microcontroller does the control task and gives additional features like setting up the room format, preloading the introductions, and so forth[5]. Automation is very important to the human assistance in any field to the busy current world. The automation should be carried in such a way that it can be easily used by people. It helps save time and pace when doing the job. Here a light controlling system is developed which replace the system used early[6] .

A homeroom computerisation is finished via mechanising the apparatus such as light, fan, cooling and projector. WAGO PLC is utilized to automate the apparatus in the room. The constant observing of different boundaries through sensors is finished by the PLC Ethernet Gateway on PC or remotely through Wi-Fi. Arduino Uno is an information securing gadget which gathers the sensor information and produce the yield signal. The yield module of the WAGO PLC produces the control sign to kill on or the type of gear. There are four PV boards to take care of the sun powered inverter. The ongoing information can be checked and vitality devoured is determined through WAGO Web Visu [1].
The sensors are used to sense the real time data for the instantaneous change in various parameters. Different sensors used here are temperature sensors, light sensors, etc. Relays are used to turn on and off the light and fan. The results obtained are stored in the PC and then displayed on the LCD display[2].

Arduino Uno is the microcontroller used for controlling the equipments. By combining all the circuits, we can automatically control the equipments in the room[3]. It uses the sensor measurements included to identify specific events that occur within the conference room depending on the available conditions, there is a basic visual, automation, and flexibility as well as real time. Introducing positive findings of smart room performance regarding user satisfaction. It illustrates many of the ways in the past in the usage and management of the intelligent room, compared to the method suggested and emphasizes new facts[4].

\section{BLOCK DIAGRAM}

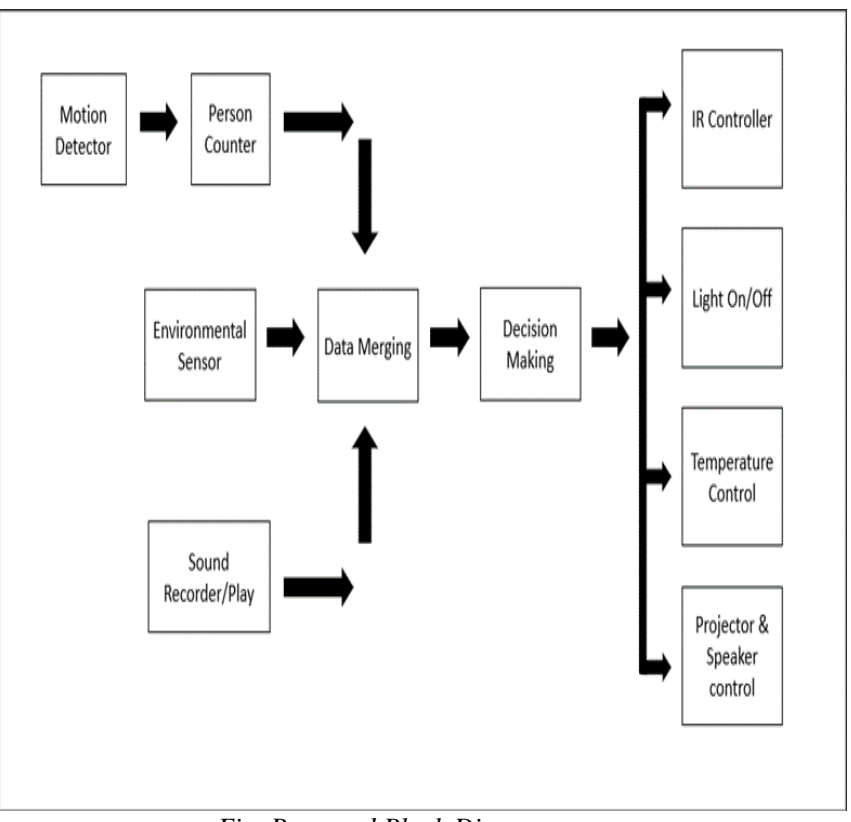

Fig. Proposed Block Diagram 


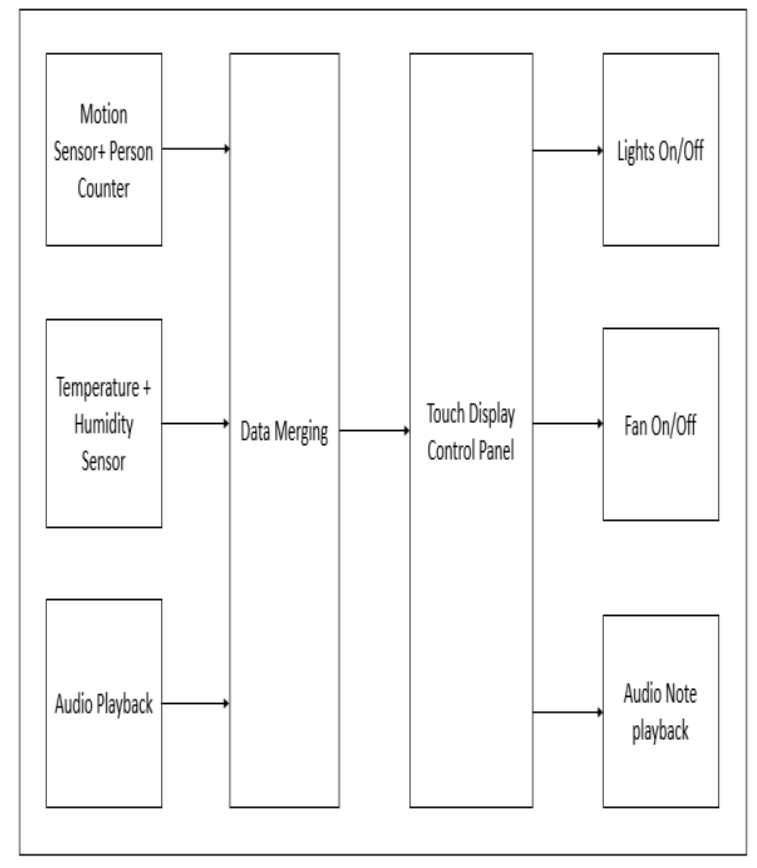

Fig. 2. Prototype Block Diagram

The Conference room is designed to be fully automated with a minimal or no interaction from users. Wi-Fi network. The automation starts the moment when the first person enters the room until all the people inside the room leaves. This is done by a counter module which is placed at the entrance which consists of IR sensors. A short introduction or a welcome speech is played back through an audio module. When the meeting starts the main lights are turned OFF and projector is turned $\mathrm{ON}$.

An automatic temperature sensing module is also placed which measures the current temperature and humidity in the room and publishes the data on to a cloud platform accordingly. Lights and fans can be switched ON or OFF as required from a control panel. Touch screen display acts as the control panel. The motor driver shield is attached on top of the Arduino UNO and is responsible for controlling fan motor. The LCD consists of 4 buttons with different operations such as Fan1, Fan2, Light1, Light2, Welcome and Thank you.

A dual channel relay is used for switching purpose. We are interfacing the smart room with the touch screen. When we switch on the circuit there is a welcome note which will be a pre-recorded digital voice message. We are controlling fans and switches through this arrangement. Light 1 and light 2 is connected to the relay. FAN is represented by a motor with a blade on its shaft.

When light 1 is pressed first led turns on. When light 2 is selected 2nd led lights up. Both can be operated simultaneously. Similarly, the fans can be operated. When we turn off or end the meeting there is a thanking note.

Arduino IDE (Integrated Development Environment): is a software platform that permits a user to program Arduino or any controller of the ATmega family. The back-end of this software is developed using JAVA. This IDE provides a user the freedom to program an Arduino using $\mathrm{C}$ language. It connects to the Arduino and hardware to upload programs and communicate with them. The main components of programming using ArduinoIDE are given below:

i. void setup: This is the location where a user can initialize all the variables that will be required during the course of programming a system. As the name suggests, this function is used to set up an Arduino before interfacing it with other circuits. This area can also be used to include libraries of various sensors.

ii. pinMode: This function is used to declare pins of Arduino as input or output.

iii. serial.begin: This function is employed when Arduino is communicating with other sensors or devices. This enables a user to set a specific baud rate for communication purpose.

iv. $\quad$ void loop (): The code written in this space will run over and over again unless Arduino is interrupted using an interrupt or the USB cable is disconnected from the USB port.

v. digitalWrite: This function is employed to form a selected pin on Arduino logically HIGH or LOW.

vi. digitalRead: This function is used when there is a need to read digital data from a sensor or when we have to control something using a switch/ push button.

vii. AnalogRead: This function comes in handy once we need to read analog data from a sensor e.g. Analog read is used when there is a need to read data from a potentiometer.

viii. AnalogWrite: This function is used when a user wants to supply analog voltages to a component. The best example of analog write is when the intensity of LED is controlled employing a potentiometer and analog write function.

\section{COMPONENTS}

The interactive monitoring and controlling system for a conference hall consists of the following components:-

\section{A. Arduino Uno}

Arduino Uno is used as the microcontroller. It is based on ATmega 328P witn 14 input/output digital pins with 6 PWM out, 6 analog inputs, crystal oscillator of $16 \mathrm{MHz}$, a USB connection, a power jack, ICSP header, and reset option. It helps to support the microcontroller connected to the computer either by a USB or power supply.External power source of about 6 to $20 \mathrm{~V}$ can be used.The power pins are VIN, $5 \mathrm{~V}, 3 \mathrm{~V} 3$ and GND.

It helps in communicating between computer, another board or with various microcontrollers. The software consists of a serial monitor which sends data to and from the board.It has a software serial library. 


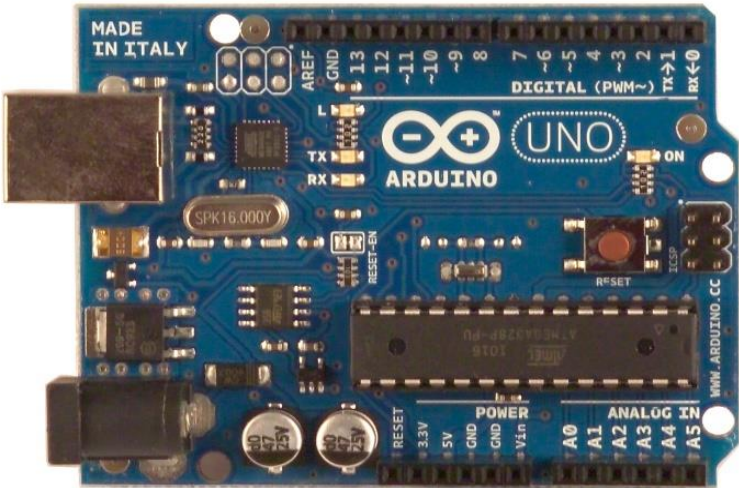

Fig. 3.Arduino UNO SMD

\section{B. DHT-22}

The DHT-22 is a basic, low-cost digital temperature and humidity sensor. It uses a capacitive humidity sensor and a thermistor to measure the surrounding air, and spits out a digital signal on the data pin (no analog input pins needed). It's easy to use, but requires careful timing to acquire data.

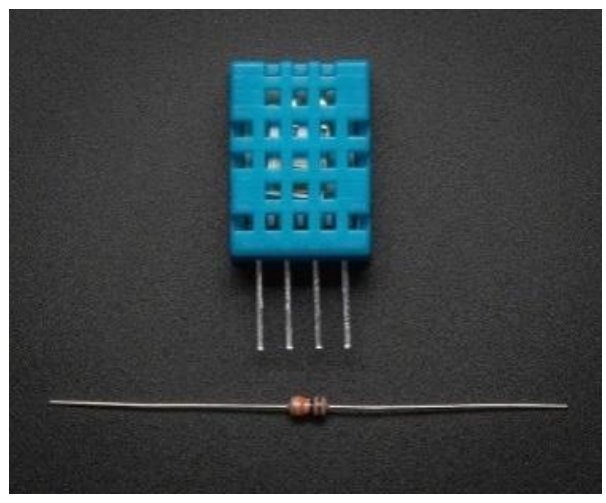

\section{C. $\quad 5 \mathrm{~V}$ Dual Channel Relay}

Fig. 4. DHT-22 SENSOR

A relay is an electromagnetic switch operated by a relatively small current that can control much larger current.This module is designed for switching two high powered devices from your Arduino. It has two relays rated up to $10 \mathrm{~A}$ per channel at $250 \mathrm{~V}$ AC or $30 \mathrm{~V}$ DC. There are two LEDs on the relay module indicating the position of the relay. Whenever a relay is activated, the respective LED will light up.

One of the best things about these relays are that the two optocouplers present in it provide good isolation between relay and Arduino. We have three channels per relay broken out to blue screw pin terminals. The channels are labelled for their function: Common (COM), Normally Closed (NC), and Normally Open (NO). The names explain the state of the channel with relation to the switch at rest.

COM (Common): This is the pin we should connect to the signal with which we are planning to switch.

NC (Normally Closed): A normally closed configuration is used when you want to turn off the relay by default. In this configuration the relay is always closed and remains closed until you send a signal from the Arduino to the relay module to open the circuit.
NO (Normally Open): A normally open configuration works the other way in which the relay is always open until you send a signal from the Arduino to the relay module to close the circuit.

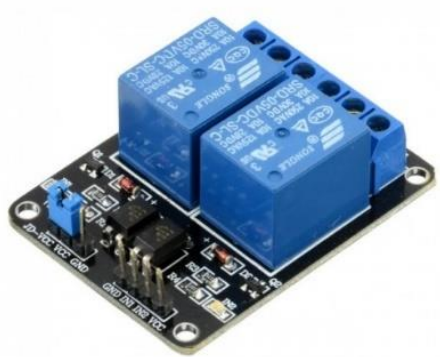

Fig. 5. 5V Dual Channel Relay

\section{L293D Motor Driver Shield}

The L293D V1 Motor Driver Shield has 4 full-bridge motor driver channels and can drive up to 4 DC motors or 2 stepper motors. It fits Arduino Uno or other Arduino with compatible I/O pins. The L293D V1 Motor Shield can drive up to $4 \mathrm{DC}$ motors at voltages from $4.5-25 \mathrm{~V}$ and at currents of up to $1.2 \mathrm{~A}$ peak ( $600 \mathrm{~mA}$ continuous) per motor with speed and direction control.

The module can also support up to 2 stepper motors. Each stepper motor takes the place of 2 of the DC motors, so you can run 2 stepper motors or 1 stepper motor and 2 DC motors or 4 DC motors.

The output channels of both the L293D chips are broken out to the edge of the shield with two 5 - pin screw terminals viz. M1, M2, M3 \& M4. You can connect four DC motors having voltages between 4.5 to $25 \mathrm{~V}$ to these terminals.

Each channel on the module can deliver up to $600 \mathrm{~mA}$ to the DC motor. However, the amount of current supplied to the motor depends on system's power supply.

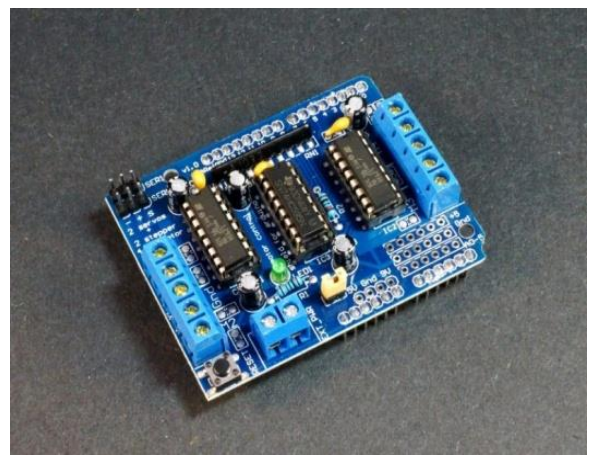

Fig. 6. L293D Motor Driver Shield

\section{E. OLED Display SSD 1306}

SSD1306 is a single-chip CMOS OLED/PLED driver with controller for organic / polymer light emitting diode dotmatrix graphic display system. It consists of 128 segments and 64 commons. This IC is designed for Common Cathode type OLED panel. The IC supports both $3.3 \mathrm{~V}$ and $5 \mathrm{~V}$ logic devices. 
The SSD1306 embeds with contrast control, display RAM and oscillator, which reduces the number of external components and power consumption. It has 256 - step brightness control. Data/Commands are sent from general MCU through the hardware selectable 6800/8000 series compatible Parallel Interface, I2C interface or Serial Peripheral Interface. It is suitable for many compact portable applications, such as mobile phone sub-display, MP3 player and calculator, etc. The IC supports both $3.3 \mathrm{~V}$ and $5 \mathrm{~V}$ logic devices

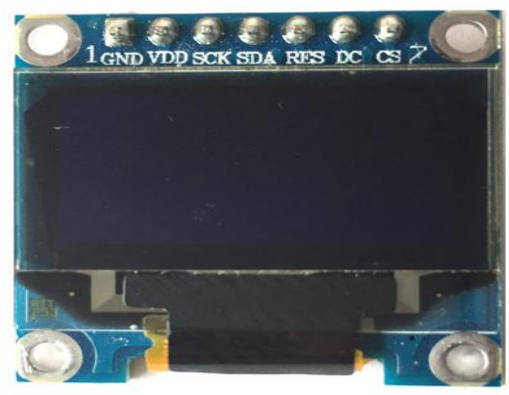

Fig. 7. OLED Display

\section{F. NEXTION Touch Display}

Designed as an ideal alternative solution for HDMI monitor. Nextion NX4832T035-3.5" HMI TFT LCD Touch Display Module is a seamless Human Machine Interface (HMI) solution that provides a control and visualization interface between a human and a process, machine, application or appliance. Nextion is mainly applied to the Internet of thing (IoT) or consumer electronics field. It is the best solution to replace the traditional LCD and LED Nixie tube.

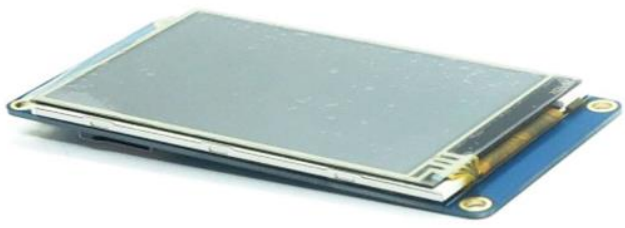

Fig. 8. Nextion 3.5” TFT Display.

\section{HARDWARE}

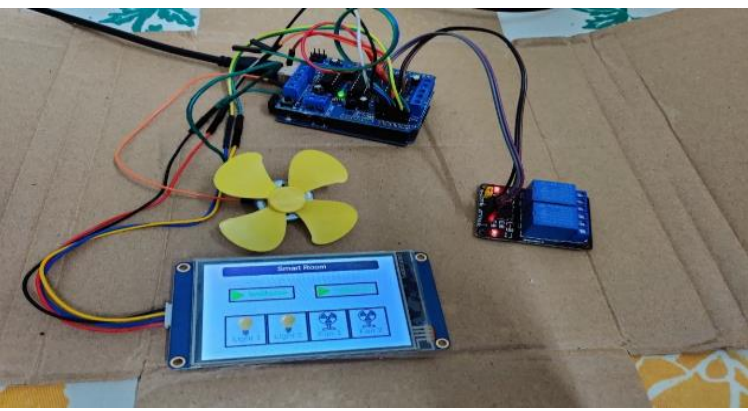

Fig. 9.Interfaced hardware components

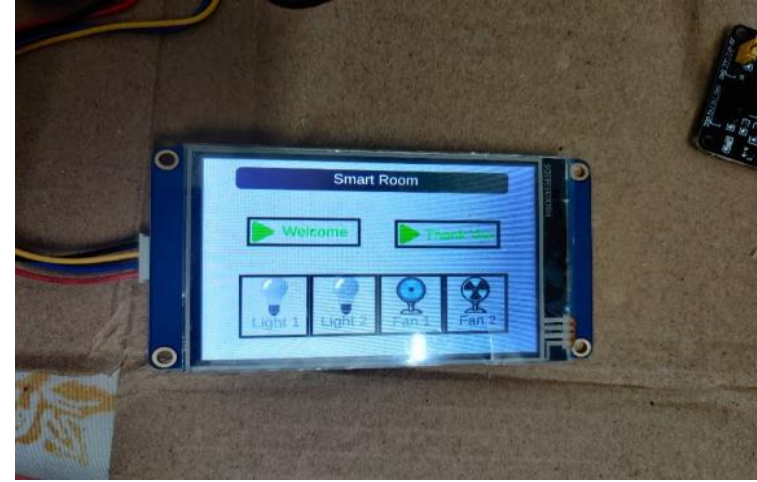

Fig. 10: Touch display.

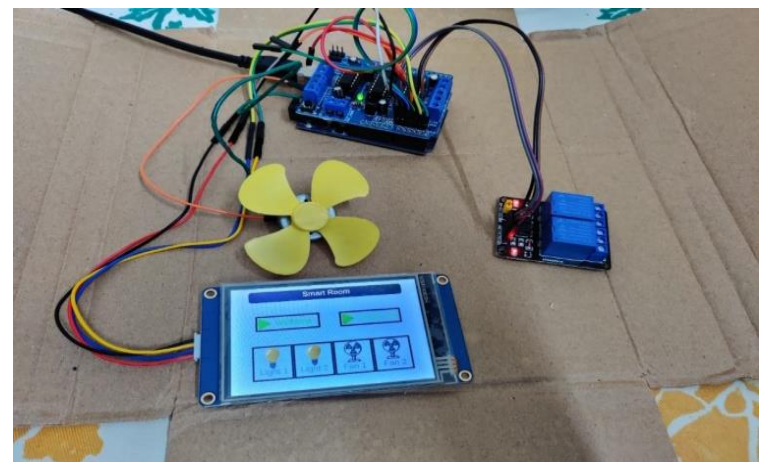

Fig. 11: Prototype

\section{ADVANTAGES}

As the main aim of our project is to automate a conference room so that there is minimal or no human interaction .This allows the user to easily manage the conference. The prototype that we have designed is made of much cheaper materials and is cost effective and it is also easy to control and access. This prototype is also designed with dedicated buttons for each connected appliances. This allows only one person to have control over the automated system which will be having more accuracy. This prototype is also easy to implement and allows a user friendly operation.

\section{CONCLUSION}

A smart conference room is an intelligent space that integrates software and hardware in the conference room itself to create an incredibly productive meeting experience for the participants. A smart conference room is a key element of smart office setup. As the room was equipped with many sensors that are connected with appropriate processing units, outputs are produced that enable certain actuations. In future we are planning to implement complex patterns that recognize events from temperature, humidity, video and energy data. We are also planning to implement this prototype in a conference room with advanced technology that counts the number of people entering the conference room and controls the room temperature by controlling the $\mathrm{AC}$ according to the people inside the room. In future we may also implement sensors that control the brightness of the room. We have completed a series of test sessions and had some initial observation that indicated the potential of the presented approach. This system has been designed with practical and 
adaptable approach that will allow more efficient and effective operation of the conference room.

\section{ACKNOWLEDGEMENT}

We express our sincere gratitude to our Project Coordinator Ms. A.V. Soumya for her guidance and support throughout this project. We also give our heartfelt appreciation to Prof. A.S. Shajilal (Head of the Department of Electrical and Electronics Engineering, Mar Baselios College of Engineering and Technology) for his valuable suggestions and support throughout this project.

\section{REFERENCES}

[1] D. M. Saravanan, "Smart Real-time meeting room," 2017 IEEE Region 10 Symposium, pp. 1-5, 2017.

[2] D.K. Rath, "Arduino Based: Smart Light Control System," International Journal of Engineering Research and General Science, 2016.

[3] S. S. Vibhuthi, "Implementation of Smart Class Room Using WAGO PLC," 2018 2nd International Conference on Inventive Systems and Control (ICISC), pp. 807-812, 2018.

[4] S. A. Renuka bhuyar, "Design and Implementation of Smart Office Automation System.," International Journal of Computer Applications, October,2016.

[5] J. S. N. D. S. C. P. Roy, "MIcrocontroller based automated room light and fan controller," Emerging trends in Electronic Devices and Computational Techniques., 2018.

[6] C. A. E. S. Giorgos S Fikas, "Creating a Smart Room using an IOT approach," 2016.

[7] P. N. Nikita Bagali, "Sensor-Based Automatic fan Controlling System and Power Consumption Analysis," International Journal of Advanced Research in Computer and Communication Engineering, vol. 5, 2016.

[8] "International Journal of Advanced Research in Electronics and Communication Engineering," vol. 6, no. 5, 2017.

[9] K. S. N. A. G. S. R. R. Nagarajan, "Intelligent Smart Home Automation and Security System using Arduino and Wi-Fi," International Journal of Engineering Computer Science, vol. 6, pp. 20694-20698, 2017. 